\title{
Review
}

\section{lonotropic receptors and ion channels in ischemic neuronal death and dysfunction}

\author{
Nicholas L WEILINGER, Valentyna MASLIEIEVA, Jennifer BIALECKI, Sarup S SRIDHARAN, Peter L TANG, \\ Roger J THOMPSON*
}

Department of Cell Biology and Anatomy, Hotchkiss Brain Institute, University of Calgary, Calgary, AB, Canada T2N 4N1

\begin{abstract}
Loss of energy supply to neurons during stroke induces a rapid loss of membrane potential that is called the anoxic depolarization. Anoxic depolarizations result in tremendous physiological stress on the neurons because of the dysregulation of ionic fluxes and the loss of ATP to drive ion pumps that maintain electrochemical gradients. In this review, we present an overview of some of the ionotropic receptors and ion channels that are thought to contribute to the anoxic depolarization of neurons and subsequently, to cell death. The ionotropic receptors for glutamate and ATP that function as ligand-gated cation channels are critical in the death and dysfunction of neurons. Interestingly, two of these receptors (P2X7 and NMDAR) have been shown to couple to the pannexin-1 (Panx1) ion channel. We also discuss the important roles of transient receptor potential (TRP) channels and acid-sensing ion channels (ASICs) in responses to ischemia. The central challenge that emerges from our current understanding of the anoxic depolarization is the need to elucidate the mechanistic and temporal interrelations of these ion channels to fully appreciate their impact on neurons during stroke.
\end{abstract}

Keywords: stroke; anoxic depolarization; ionotropic receptors; NMDA receptors; P2X7 receptors; ion channels; pannexin channels; TRP channels; acid-sensing ion channels (ASICs)

Acta Pharmacologica Sinica (2013) 34: 39-48; doi: 10.1038/aps.2012.95; published online 6 Aug 2012

\section{Introduction}

Ischemia is a consequence of the loss of blood flow to tissues or organs. The principle result is a restriction in the delivery of the energy substrates, oxygen and glucose, to cells in the affected area. It is important to note that ischemia also causes several other detrimental stimuli, including acidosis (hypercapnia) and cessation of blood flow that is likely important for regulation of vascular tone. In the laboratory in vitro setting, ischemia is typically modelled as its constituent components, anoxia, hypoglycemia, $\mathrm{O}_{2}$ /glucose deprivation (OGD), or acidification; the primary reason being that it makes dissecting the complex molecular mechanisms of cellular death and dysfunction more tractable.

In the brain, ischemia occurs as a consequence of stroke or cardiac arrest. One of the early, major effects of ischemia on neurons is the appearance of a large inward current that is carried by cation influx, and is responsible for the anoxic depolarization (AD). The AD can be measured in vitro and in vivo, and consists of a rapid loss of membrane potential,

\footnotetext{
* To whom correspondence should be addressed.

E-mail rj.thompson@ucalgary.ca

Received 2012-04-06 Accepted 2012-06-08
}

unregulated calcium influx, loss of the neuron's ability to produce ATP and characteristic dendritic and axonal beading ${ }^{[1-3]}$. The focus of this review is to summarize the roles of some of these cation channels and their contribution to the AD and its inward currents. Specifically, glutamate-gated ion channels, ATP-binding purinergic receptors, pannexin1 channels, and other channel mediators (TRP and ASIC) will be discussed. One central challenge of the field is to reconcile the temporal and mechanistic relationships of these various ion channels, so that effective therapeutics for neuroprotection and enhanced recovery can be developed.

\section{Glutamate-gated ionotropic receptors and ischemia}

The longstanding paradigm of ischemia-induced cell death has been that uncontrolled opening of ionotropic glutamate receptors induces excitotoxcity, and that this death of neurons by over-activation is responsible for the neurological deficits following stroke. In response to increased release of presynaptic glutamate $^{[4]}$ or reversal of uptake mechanisms in astrocytes ${ }^{[5]}$, there is an accumulation of extracellular glutamate and subsequent over-stimulation of post-synaptic $N$-methyl- $D$-aspartate (NMDA) and 2-amino-3-(5-methyl-3-oxo-1,2-oxazol-4-yl)propanoic acid (AMPA) receptors that mediate cationic inward 
currents (Figure 1).

NMDA receptors (NMDARs) are cation permeable ligandgated ion channels that have prominent roles in physiological synaptic functions. Activation of NMDARs contributes to the plasticity of synaptic strength, and by extension, the sub-cellular mechanisms underlying some forms of learning and memory. NMDARs are unique from other ligand-gated ion channels insofar as they are "coincidence detectors"; not only do they require glutamate and glycine (or D-serine) as co-agonists to induce channel opening ${ }^{[6-9]}$, but they also need

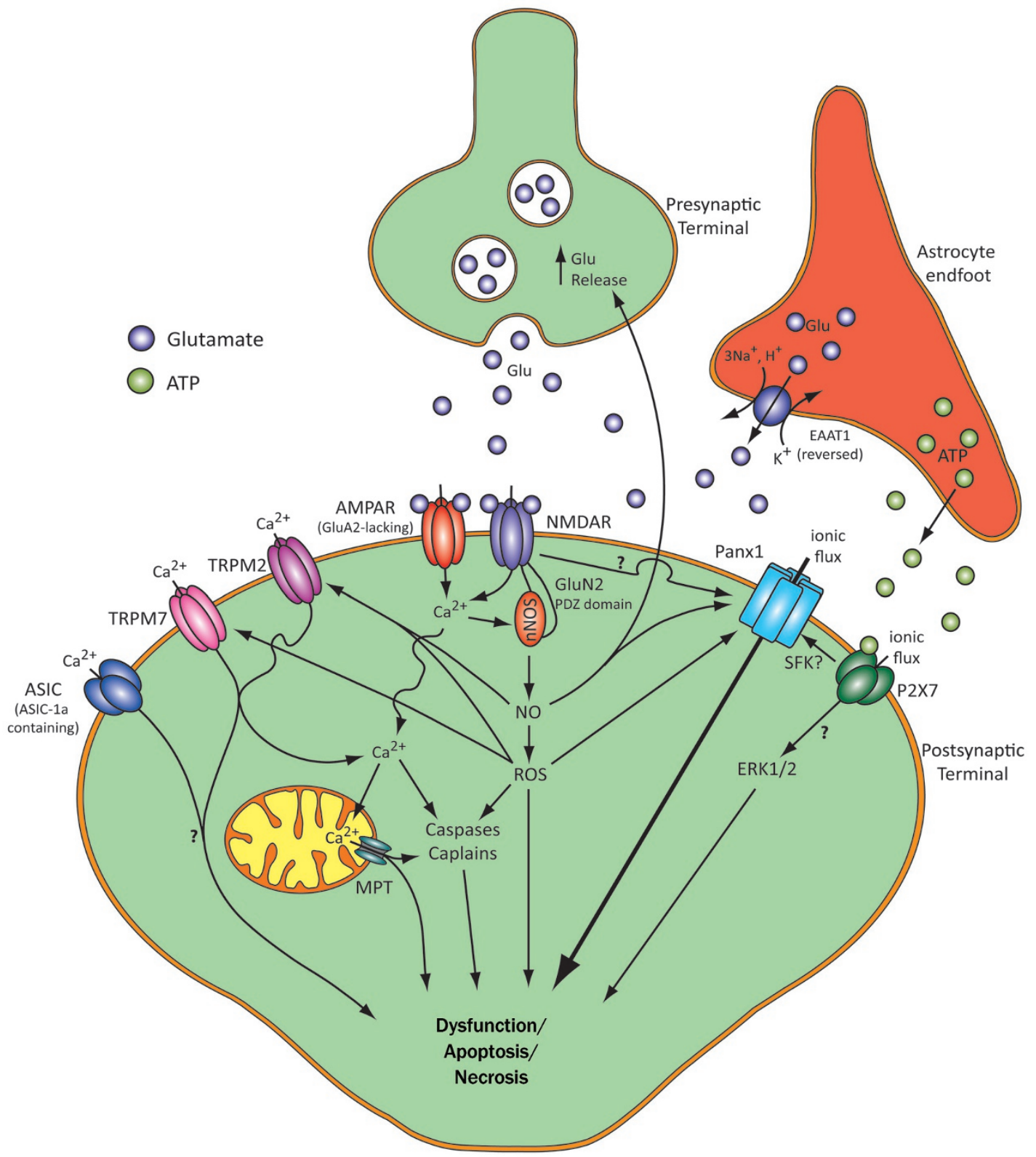

Figure 1. Key ion channels that contribute to cell death signaling cascades during ischemia. For clarity, channels in the post-synpatic membrane are highlighted, but it is important to note that both pre-synpatic and astrocytic channels are also likely critical. Ischemia triggers enhanced presynaptic glutamate release and reversal of the astrocytic glutamate reuptake transporter (EAAT1), amounting to a dramatic increase in glutamatergic signaling via postsynaptic NMDARs and AMPARs. $\mathrm{Ca}^{2+}$ through NMDARs and GluA2-lacking AMPARs can stimulate NO production by Ca ${ }^{2+}$-dependent nNOS, which can react with reactive oxygen species (ROS) to form highly damaging intermediates. NO and NO-ROS reaction products (i.e. peroxynitrite) may activate TRPM2/7 and Panx1 channels. Retrograde diffusion of NO can enhance presynaptic glutamate release, further exacerbating postsynaptic excitotoxicity. Decreases in extracellular $\mathrm{pH}$ leads to ASIC opening and $\mathrm{Ca}^{2+}$-influx (for ASIC-1a homomers), which may in turn contribute to cell death. Increases in extracellular ATP concentrations stimulate P2X7 opening, possibly activating Panx1 channels via Src Family Kinases (SFK), as well as stimulating ERK1/2 function to induce cell death. Activation of any/all of the ion channels mentioned here will yield an increase in intracellular $\mathrm{Ca}^{2+}$ levels, which can activate downstream caspases, calpains, and trigger mitochondrial permeability transition; all of which have been implicated in neuronal dysfunction/apoptosis/necrosis. 
a concurrent membrane depolarization to alleviate a voltagesensitive $\mathrm{Mg}^{2+}$ block in the pore ${ }^{[10]}$. NMDAR opening allows influx of $\mathrm{Na}^{+}$(which will contribute to membrane depolarization), and more importantly $\mathrm{Ca}^{2+}$ influx, which mediates subsequent physiological as well as pathophysiological effects.

NMDARs are heterotetramers comprised of GluN1 (ubiquitously expressed), GluN2(A-D) and GluN3(A-B) subunits; the resultant receptor composition will govern $\mathrm{Ca}^{2+}$ permeability, and the affinity of $\mathrm{Mg}^{2+}$ for the pore and glutamate and glycine at their ligand-binding sites ${ }^{[11-14]}$. In that light, NMDAR contribution to glutamate excitotoxicity is thought to be directly dependent on subunit expression. For example, GluN3Acontaining NMDARs are impermeable to $\mathrm{Ca}^{2+}$, have decreased $\mathrm{Mg}^{2+}$ block ${ }^{[11,15]}$, and have been reported to be neuroprotective during ischemia ${ }^{[16]}$.

$\mathrm{Ca}^{2+}$ conductance through NMDARs can promote both apoptotic and necrotic pathways. One means through which NMDARs achieve this is via direct activation of neuronal nitric oxide synthase (nNOS; Figure 1), which is anchored in a complex with NMDARs via a PSD-95 binding domain on the C-terminus of GluN2 subunits ${ }^{[17]}$. $\mathrm{Ca}^{2+}$ currents through NMDARs transiently activate nNOS to produce nitric oxide (NO), which subsequently activates a plethora of cascades. NO production directly induces ATP depletion by inhibiting mitochondrial cytochrome oxidase, by generating reactive oxygen species (ROS), and enhancing presynaptic glutamate release through retrograde signalling ${ }^{[18-20]}$. Concurrent increases in intracellular $\mathrm{Ca}^{2+}$ and ROS may also lead to mitochondrial permeability transition (and thus cytochrome $c$ release), as well as activating caspases and calpains, which trigger apoptosis and necrosis ${ }^{[21,}$ 22] (Figure 1).

It is by no means a stretch to conclude that activation of NMDARs plays a crucial role in perpetuating cell death pathways, and yet clinical development of NMDAR-targeting pharmacological interventions was ineffective in treating or minimizing stroke damage in patients. In spite of the considerable promise of neuroprotection of NMDAR block from in vitro and in vivo animal studies, clinical trials on all NMDAR antagonists were halted due to lack of efficacy ${ }^{[23,24]}$. NMDARs are not, however, the sole conduit for $\mathrm{Ca}^{2+}$ entry during ischemia (see below), and therefore targeting $\mathrm{Ca}^{2+}$-signalling cascades may be a more strategic approach to blocking neuronal death. Emerging evidence suggests key differences between neuronal responses to activation of synaptic or extrasynaptic NMDARs. The more-abundant, extrasynaptic NMDARs promote cell death ${ }^{[25]}$, while synaptic NMDARs might in fact be neuroprotective through $\mathrm{Ca}^{2+}$ dependent activation of CREB (for recent review, see ${ }^{[26]}$ ).

In addition to NMDARs, AMPA receptors are also proposed to mediate cell death during ischemia ${ }^{[27]}$. AMPARs are tetrameric ligand gated ion channels, composed of a combination of GluA1-4 subunits and, unlike NMDARs, are activated solely by glutamate binding. Though historically not considered to be as critical as the NMDAR in perpetuating excitotoxic cell death, AMPARs may also mediate (or initiate) pathological cationic influx. Indeed, early studies on rodent models have shown that administration of AMPAR antagonists can be neuroprotective during ischemia ${ }^{[28,29]}$. One key feature that differentiates some AMPARs from NMDARs is the inability of GluA2 containing AMPARs to conduct $\mathrm{Ca}^{2+}$, reducing the possibility of activating $\mathrm{Ca}^{2+}$-mediated neurotoxic cascades directly. However, AMPARs may contribute indirectly to neurotoxic cascades through membrane depolarizations that are sufficient to remove the $\mathrm{Mg}^{2+}$ block of NMDAR and facilitate opening or by recruitment of other $\mathrm{Ca}^{2+}$ influx pathways.

The majority of AMPARs expressed in neocortical and hippocampal pyramidal neurons are GluA2-containing channels $^{[30-32]}$, a subunit that contains a positively charged arginine ( $\mathrm{R})$ in the pore forming domain of the channel, rendering the AMPAR impermeable to $\mathrm{Ca}^{2+}$ ions ${ }^{[33]}$. Transgenic expression of a glutamine (Q) in lieu of arginine (R) on GluA2 is permissive of $\mathrm{Ca}^{2+}$ conduction ${ }^{[34]}$; prolonged opening of GluA2(Q)-containing AMPARs (and not GluA2(R) receptors), are proposed to play a pivotal role during ischemic cell death $^{[34]}$. On the other hand, GluA2-lacking receptors (consisting of GluA1, GluA3, or GluA4) are permeable to divalent $\mathrm{Ca}^{2+}$ and $\mathrm{Zn}^{2+}[35,36]$, and are strongly implicated in global ischemia/ glutamate excitotoxicity in vivo ${ }^{[37]}$.

AMPAR trafficking and subunit assembly are dynamic processes under both physiological (for example, in long-term potentiation and depression) and pathophysiological conditions (for review, see ${ }^{[38]}$ ). Regulation of AMPARs has been extensively studied during neurodegenerative conditions, such epilepsy, brain trauma, and ischemia. Notably, surface expression of GluA2-containing AMPARs is downregulated following ischemic insult, with a subsequent increase in AMPAR-mediated $\mathrm{Ca}^{2+}$ influx (by GluA2-lacking AMPARs) following global ischemia ${ }^{[39,40]}$. Similar to NMDARs, activation of AMPARs have also been shown to induce NO production via $\mathrm{nNOS}^{[41]}$, as well as $\mathrm{Ca}^{2+}$-dependent calpain activity in culture $^{[42]}$. Contrary to this, AMPA stimulation might promote neuroprotection through CREB and BDNF activity ${ }^{[43]}$. Thus, it is clear that GluA2-lacking AMPARs confer a significant role in mediating cell death during glutamate excitotoxicity, which is likely occurring through $\mathrm{Ca}^{2+}$-dependent pathways analogous to those seen in NMDAR overstimulation.

\section{Purinergic receptors}

There are two major groups of purinergic receptors, adenosine-gated P1 and P2 that are opened by uridine tri and di-phosphates as well as adenosine ${ }^{[44,45]}$. The P1 receptors are metabotropic and include the $A_{1}$ and $A_{3}$ subtypes, which enhance phospholipase $C$ activity and inhibit adenylyl cyclase, and the $A_{2 A}$ and $A_{2 B}$ subtypes that enhance production of cAMP. The P2 receptors comprise both the ionotropic P2X, and metabotropic G protein-coupled P2Y receptors. The P2 family are widely expressed in tissues and in diverse cell types, including neurons, astrocytes, microglia and oligodendrocytes in the central nervous system. Both adenosine and adenosine-5' -triphosphate (ATP) can signal in physiological and pathological conditions and whether this is neuroprotective or neurodegenerative depends upon the receptor subtypes 
involved $^{[44,45]}$.

Following the onset of ischemia, the intracellular concentration of ATP decreases ${ }^{[46,47]}$, resulting in a dramatic ionic imbalance and subsequent anoxic depolarization-like events ${ }^{[48]}$. This is associated with enhanced glutamate (see above) and ATP release into the extracellular milieu ${ }^{[49]}$, resulting in activation of P2 receptors. After prolonged activation, P2X7 receptor function can transition from a small, cation permeable channel to one with characteristics of a significantly larger, non-specific pore ${ }^{[50,51]}$. Several models for how this occurs have been proposed (reviewed in ${ }^{[52]}$ ), the most recent involving the recruitment of pannexin-1 (Panx1) channels ${ }^{[53,54]}$ (reviewed in ${ }^{[55]}$; see below).

Disruption of the membrane, as well as apparent activation of Panx1 permits rapid efflux of ATP from the cytosol to the extracellular space. The physiological concentration of ATP is typically high in neurons (millimolar range) - ischemia can induce a rapid increase in extracellular ATP to cytotoxic levels, such that cells (which are uninjured initially) can rapidly succumb to cell death ${ }^{[56,57]}$. In addition to release of ATP through Panx1, the purine may also leave neurons and astrocytes by several other mechanisms, including permeation through connexin hemichannel's exocytosis ${ }^{[58-61]}$, and via the ABC transporters/osmolytic transporters that are linked to anion channels ${ }^{[62,63]}$. Regardless of the exact mechanism of release, it is clear that excessive ATP can contribute to cell death due to recruitment of a 'death complex' that includes $\mathrm{P} 2 \mathrm{X} 7$ receptors and Panx $1^{[64,65]}$.

There are several studies that demonstrate upregulation of purinergic receptors and neuroprotective effects of antagonizing ATP signalling during ischemia and brain injury (extensively reviewed $\mathrm{in}^{[66]}$ ) - for the purpose of this review, we will only mention the most recent studies. Ischemia reportedly elevates expression of several P2 receptors (P2X1, 2, 4, 7 , and P2Y4) in dissociated neuronal or organotypic cultures, suggesting that these subunits may be important for pathological responses to ATP during insults ${ }^{[67-69]}$. In support of this notion, block of P2X7 during focal ischemia reduced infarct size $^{[70]}$ and, analogous to neuroprotection, protected optic nerve oligedendrocytes from ischemic damage ${ }^{[71]}$.

The non-selective P2 receptor antagonists, PPADS (pyridoxalphosphate-6-azophenyl-2', $4^{\prime}$-disulfonate) and suramin decreased infarct size and facilitated functional recovery following animal stroke models ${ }^{[72-74]}$. Similar effects have been reported in vitro, where inhibition of P2Y1, P2X3, and P2X7 receptors in rat hippocampal slices exposed to OGD significantly attenuated depression of field excitatory postsynaptic potentials (fEPSPs) and anoxic depolarizations ${ }^{[75]}$. The same study also demonstrated that downstream activation of the kinases ERK1/2 was involved in synaptic failure and neuronal damage. Interestingly, activation of purinergic receptors by ATP may also be neuroprotective. ATP released during cortical spreading depression was reported to activate P2Y receptors, followed by synthesis of new proteins, which in turn exerted neuroprotective effects, possibly through preconditioning $^{[60]}$.
Under normal conditions, adenosine typically inhibits neuronal excitability by attenuating evoked release of glutamate from the presynaptic neuron ${ }^{[76-78]}$. The effects of adenosine receptor activation, similar to $\mathrm{P} 2 \mathrm{X} / \mathrm{P} 2 \mathrm{Y}$ receptors, are reported to be both protective and detrimental. For example, inhibition of $\mathrm{A}_{2 \mathrm{~A}}$ signalling in a model of focal ischemia is thought to be neuroprotective ${ }^{[79]}$, while ischemic brain injury was reduced by activation of $\mathrm{A}_{3}$ receptors ${ }^{[80]}$.

Ischemic elevation of extracellular adenosine may be due to increased activity/expression of exonucleotidase, which participates in hydrolysis of ATP to adenosine ${ }^{[81-83]}$. It is likely therefore, that the release of ATP and adenosine under ischemic conditions is mechanistically and temporally separated $^{[49]}$, suggesting that the initial elevations in ATP can activate neurodegenerative mechanisms that may be followed, after conversion of ATP to adenosine by neuroprotective and neurodegenerative roles for the purines. However, this appears to be strongly dependent upon CNS region, animal model and the type of insult, and requires more investigation to elucidate these complex mechanisms ${ }^{[80,84-96]}$.

\section{Pannexin channels}

The pannexin family of proteins was first identified by Panchin et $a l^{[97]}$ over a decade ago by using a degenerate PCR strategy in a search for vertebrate homologs of invertebrate gap junctions (innexins). It is now known that there are three family members (Pannexin-1, -2, and -3) with differential tissue distributions. Northern blot analysis shows that Pannexin-1 (Panx1) mRNA is found in wide variety of tissues, and has high expression levels in the brain and immune cells ${ }^{[98]}$. Expression of Panx 2 mRNA on the other hand, is restricted to the brain and appears to have an intracellular distribution when modified by $S$-palmitoylation in neural progenitor cells $^{[98,99]}$. Alignment of mRNA and amino acid sequences demonstrate significant similarity between Panx3 and Panx1 with Panx3 being more closely related to Panx1 than Panx2, but the tissue distribution of Panx3 appears to be limited to synovial fibroblasts and osteoblasts ${ }^{[98]}$.

The first indications that Panx1 channels were involved in anoxic depolarizations came from our work ${ }^{[100]}$ where we showed using acutely isolated hippocampal neurons that OGD activated Panx1 channels. The main implications of this work were that Panx1 channels could be directly activated by ischemia, and the mechanism by which this activation occurred was independent of ligand-gated receptors because blocking NMDA, AMPA and P2X7 receptors failed to alter the large anoxic depolarization's inward currents activated by OGD ${ }^{[100]}$. It was later suggested that Panx1 opening in isolated neurons was mediated by the production of NO, and the authors' predicted that this could involve a nitrosylation reaction ${ }^{[101]}$. However, the mechanism by which NO acts on Panx1 to mediate channel opening during ischemia has not been identified. One intriguing possibility is that cysteine residues in the C-terminal are involved in activation of Panx1 by NO because mutation of C346 produced constitutively active channels and cell death ${ }^{[102]}$. 
Is Panx1 activation important for neuronal death during stroke? This question has taken some time to answer considering that the first description of Panx 1 activation by ischemia was in 2006. Recently, two groups from Heidelberg, the Monyer and Schwaninger labs collaborated to show that genetic deletion of both Panx1 and Panx2 decreased stroke lesion volumes in mice subjected to permanent middle cerebral artery occlusion ${ }^{[103]}$. These results were both exciting and intriguing. The exciting part is, of course, that knockout of pannexin channels contributed to neuroprotection in stroke. The intriguing part lies in the observations that Panx1/2 knockouts appear phenotypically normal (i.e. breed normally and don't have any obvious behavioural abnormalities), and that both channels had to be knocked out to detect significant neuroprotection. Given the wide distribution in Panx1 tissue expression, one might expect a more deleterious effect when not present. This suggests that there may be some developmental compensation for deletion of pannexins. Another possibility, is that there is no normal physiological role for pannexins. This however, seems highly unlikely because data are emerging that Panx1 is involved in ATP release from cells ${ }^{[104,105]}$ and is important in regulating proliferation of neuronal stem cells ${ }^{[106]}$.

How are pannexins being activated during stroke? Clearly a stroke in the brain is much more complicated than just OGD of isolated neurons. As described above, one of the central consequences of ischemic exposure is the uncontrolled release of the neurotransmitters, glutamate and ATP. In 2008, we described a role for the NMDA receptor in activating Panx1, which contributed to interictal (ie aberrant bursting) in hippocampal pyramidal neurons in acute brain slices ${ }^{[107]}$. This work demonstrated that Panx1 can be involved in neuronal plasticity, but also that over-stimulation of NMDA receptors can recruit Panx1, implicating Panx1 channels in excitotoxic neuronal death (Figure 1). It is important to note that direct demonstration of an NMDAR-Panx1 role in excitotoxicity has not yet been shown, but is certainly suggested by the work of Bargiotas et al ${ }^{[103]}$ in Panx1/2 knockout mice. Furthermore, the intermediary mechanism(s) that couple NMDARs to Panx1 have not yet been characterized.

Interestingly, the purinergic receptor, $\mathrm{P} 2 \mathrm{X} 7$ can directly couple to Panx1, although the mechanistic details, like NMDARPanx1, remain unknown. The nature of the role of Panx1 in functioning as the large pore of the P2X receptors is still controversial and has been reviewed elsewhere ${ }^{[55]}$ so it will not be the focus here. Regardless of whether or not Panx 1 is the "large pore mode" of the P2X7 channel, it is clear from work from several labs that P2X7 receptors can induce opening of Panx $1^{[108-112]}$. In J774 cells, this appears to involve the Src family of protein tyronsine kinases $\left(\mathrm{SFKS}^{[110]}\right)$. It has also been reported that SFK activity is increased during ischemia, suggesting that in neurons expressing both P2X7 and Panx1, SFKs could play a role in neuronal death ${ }^{[113,114]}$. Other studies, however, also suggest that SFKs may have a neuroprotective role following ischemic insult by a mechanism that may involve regulation of ERK and stimulating proliferation of dentage gyrus neuronal cells $s^{[15,116]}$. The relationship between pannexin channels and purinergic receptors was further demonstrated in the study by Kawamura Jr et al ${ }^{[117]}$, who uncovered a significant contribution of Panx1 to neuronal excitability through ATP release.

Mechanisms governing Panx1 activation, other than recruitment by ligand-gated ion channels, have also been proposed. These include truncation of the Panx1 C-terminal by caspases. Chekeni et al ${ }^{[64]}$ suggested Panx1 was responsible in part for the release of ATP and UTP during apoptosis, which recruits monocytes and macrophages. In their model, Chekeni et al, propose that Panx1 is targeted for cleavage at the C-terminus by caspase- 3 and -7 , resulting in channel opening, and consequential purine release. Thus, Panx 1 can release "find-me" signals to immune cells during apoptosis. Interestingly, Panx1 was not required for the apoptotic process, but rather seems to act as the pathway for release of death signals ${ }^{[118]}$. Panx1 may also be opened by rises in extracellular $\mathrm{K}^{+}$, independently of membrane depolarization and contribute to seizure phenotypes ${ }^{[119]}$. Similarly, in a more recent study by Gulbransen et $a l^{[109]}$, we show that Panx1 is involved in death of neurons in the enteric nervous system (gut) following inflammation models of Crohn's and colitis. The mechanism of neuronal death is however, not clear but appears to involve activation of the inflammasome ${ }^{[53]}$.

\section{Transient receptor potential (Melastatin) channels}

Transient receptor potential (TRP) channels are a family of tetrameric cation-permeable channels that employ unique mechanisms of activation, spanning mechanosensation (membrane stretch), temperature, and naturally occurring exogenous agonists ${ }^{[120,121]}$. These channels are expressed throughout the nervous system, and have been noted to play a critical role in delayed cell death after ischemic insult in the $\mathrm{CNS}^{[122]}$. The TRP channel family consists of six main subfamilies, and are involved in a whole host of processes (downstream of $\mathrm{Ca}^{2+}$ influx) such as sensation, cell proliferation and fertility ${ }^{[123]}$. Two species of TRP channels from the TRPM (Melastatin) super family including TRPM2 and TRPM7, have been reported to contribute to neuronal cell death in the brain ${ }^{[124]}$.

Cell death due to TRPM2 and TRPM7 appear to be a consequence of delayed calcium dysregulation following ischemia $^{[124]}$ (Figure 1). TRMP2 can be activated by arachidonic acid, reactive oxygen species (ROS), nitric oxide (NO) and adenine $5^{\prime}$-diphosphoribose (ADPR), while TRPM7 is activated by various components involved in stroke such as peroxynitirite, free radicals and change in extracellular $\mathrm{pH}^{[125]}$. TRPM2 and TRPM7 are permeable to $\mathrm{Ca}^{2+}$ while TRPM2 is also permeable to $\mathrm{Na}^{+}$and $\mathrm{K}^{+[126]}$. TRPM7 is also thought to mediate the influx of other divalent metals such as $\mathrm{Zn}^{2+}$ and is also permeable to $\mathrm{Mg}^{2+}{ }^{2127]}$. Conductance of $\mathrm{Zn}^{2+}$ and $\mathrm{Mg}^{2+}$ by TRPM7 occlude monovalent ions from permeating through the pore ${ }^{[122]}$. Unlike TRPM2, which produce a linear currentvoltage curve, TRPM7 currents exhibit a large outward rectification $^{[124]}$. However, this outward rectification will linearize when divalent cations, such as calcium, are absent from 
the extracellular space ${ }^{[124]}$, which may allow for opening of the channel at resting potentials or under pathophysiological conditions such as ischemia.

TRPM7 was shown by Aarts et al (2003) to mediate a cation current $\left(I_{\mathrm{OGD}}\right)$ that the authors reported to be lethal to neurons ${ }^{[122]}$. This current arises under conditions of OGD and is activated by ROS, which increases $\mathrm{Ca}^{2+}$ uptake by the neuron $^{[122]}$ (Figure 1). Furthermore, the use of antiexcitotoxic therapy (AET), with drugs such as MK-801, CNQX and nimodipine, could protect neurons from death if given one hour prior to stroke $\mathrm{e}^{[128]}$. When TRPM7 was knocked down in culture by siRNA, cell death due to anoxia decreased significantly even without the use of $\mathrm{AET}^{[122]}$. This demonstrates the importance of TRPM7 in in vitro models of toxicity, such that when TRPM7 is inhibited or silenced there is increased neuronal survival during ischemia ${ }^{[122]}$. The importance of TRPM7 channels in neuronal death using in vivo stroke rodent models has been shown by either silencing TRPM7 directly or when its activation (among other pathways) was disrupted with use of a PSD-95 interfering peptide ${ }^{[129,130]}$. A recent and exciting report shows that disruption of TRPM7/PSD95/neuronal nitric oxide synthase with the NR2B C-terminal mimetic peptide dramatically reduced focal stroke damage in primates ${ }^{[129]}$. Taken together, these studies have demonstrated a clear role for TRPM7 in neuronal death caused by OGD.

TRPM2 channels are also strongly implicated in neuronal death through a mechanism that involves a large calcium influx induced by oxidative stress, exogenous hydrogen peroxide $\left(\mathrm{H}_{2} \mathrm{O}_{2}\right)$, or tumor necrosis factor a (TNF-a $)^{[131]}$. Zhang et al (2003) activated an isoform of TRPM2 with $\mathrm{H}_{2} \mathrm{O}_{2}$ that caused cell death in expression systems ${ }^{[132]}$. Consistent with this, when TRPM2 was either pharmacologically inhibited or knocked down by shRNA strategies, there was reduced calcium influx and greater cell survival. An increase in cortical levels of TRPM2 mRNA has also been reported following ischemia, but whether or not this is detrimental to neuronal survival in vivo is unclear ${ }^{[133]}$, and it appears that TRPM2 is important for oxidative stress induced cell death. A role for TRPM2 in neuronal death in vivo is clearly the logical next step to confirm the importance of these channels.

\section{Acid sensing ion channels}

A critical consequence of ischemia during stroke is acidosis, resulting primarily from lactate production when oxidative phosphorylation fails and neurons switch to glycolysis ${ }^{[134]}$. This decrease in $\mathrm{pH}$ to values below 6 can be an important cause of cell death ${ }^{[135]}$. Although the effects of acidification have been less intensly investigated compared to OGD, recent reports suggest that decreases in tissue $\mathrm{pH}$ during ischemia may trigger the opening of acid sensing ion channels (ASICs). The ASICs can facilitate sodium and calcium influx and thereby contribute to ionic dysregulation ${ }^{[136,137]}$.

ASICs are ligand-gated ion channels that are part of the epithelial sodium channel family $(\mathrm{ENaC})$ and are activated by low extracellular $\mathrm{pH}^{[138,139]}$. The recently resolved structure of ASIC1 shows a trimeric channel with each ASIC subunit having two transmembrane domains and a large extracellular loop comprising 350-370 amino acids ${ }^{[140-142]}$. Expression of ASICs appears limited to the peripheral and central nervous systems of chordates; non-neural cells and other phyla fail to express the channel ${ }^{[143]}$. To date, four genes (ASIC1-ASIC4) are known to code for the six different ASIC subunits (ASIC1a, $-1 b,-2 a,-2 b,-3,-4)^{[138,139]}$. Four of the ASIC subunits (ASIC1a, $1 \mathrm{~b}, 2 \mathrm{a}$, and 3) can form functional homomeric channels, each having different biophysical properties ${ }^{[138,139]}$. Although all ASIC channels conduct $\mathrm{Na}^{+}$upon activation and exhibit differential sensitivities for $\mathrm{pH}$, only ASIC1a homomeric channels are $\mathrm{Ca}^{2+}$ permeable ${ }^{[134,136,137]}$.

Block of ASIC1a contributes to neuroprotection in animal models of stroke ${ }^{[136,137,144,145]}$. Cultured cortical neurons subjected to OGD elicit inward currents that could be inhibited by ASIC1a antagonists, amiloride or PcTx venom ${ }^{[136]}$. Additionally, exposure of cortical neurons to $\mathrm{pH} 6.0$ in the presence of glutamatergic and voltage-sensitive calcium channel blockers leads to an increase in intracellular $\mathrm{Ca}^{2+}$ that is sensitive to ASIC1a blockers, amiloride or psalmotoxin ${ }^{[136]}$. In vivo, occlusion of the middle cerebral artery in knockout mice lacking ASIC1a had smaller infarct sizes compared to control animals ${ }^{[136]}$. In addition, it appears that ASICs are not only involved in mediating neurotoxicity during the ischemic event (Figure 1), but that blocking ASIC1a activity up to $5 \mathrm{~h}$ post reperfusion significantly reduced infarct volumes ${ }^{[144]}$, suggesting an ongoing neurodegeneration due to ASIC1a activation. Thus, ASIC1a opening during ischemia may be a crucial mediator of acidosis-induced neuronal death.

Gao et al demonstrated that there is an ischemia-induced enhancement of ASIC1a activity due to phosphorylation of Ser478 and Ser479, which enhances permeability to cations ${ }^{[145]}$. It is well known NMDARs are activated during ischemia (see above) ${ }^{[134]}$ and it appears that activation of NMDARs containing the NR2B subunit causes a cascade that recruits $\mathrm{Ca}^{2+} /$ calmodulin dependent protein II (CaMKII), which phosphorylates ASIC1 $\mathrm{a}^{[145]}$. Moreover, preventing the increased ischemia-induced permeability of ASIC1a by applying NR2B or CaMKII antagonists leads to decreased intracellular calcium and decreased neuronal death ${ }^{[145]}$. In addition to the NMDARCaMKII cascade, extracellular spermine and dynorphin appear to mediate ASICla channel opening either during, or immediately following ischemia ${ }^{[146,147]}$. Taken together, it appears that ischemia-mediated acidosis triggers ASIC1a channel opening that may mediate an alternative, glutamate receptor independent (but NR2b-modulated) calcium influx pathway. Block of ASIC-1a channels during ischemia could, therefore, lead to better functional outcomes in individuals who have suffered stroke.

\section{Concluding remarks}

Here we have discussed several key channels thought to be involved in ischemia mediated neuronal damage. One of the interesting themes emerging from the past several decades of work is that the ligand gated cation channels, NMDARs, P2XRs (and others) may couple directly to pannexin- 1 chan- 
nels, which would be important for potentiating the excitotoxic effects of receptor overstimulation. It is important however to remember that several other ion channels are critically involved, including members of the TRP and ASIC families and that both of these can be regulated or modulated by the NMDAR. It remains a challenge of the field to determine the mechanisms of activation of many of these channels and to quantify their temporal relationships during stroke. In particular, separation of the contribution of direct activation of channels by ischemia-induced intermediates versus activation by coupling to ligand-gated channels is critical.

\section{Acknowledgements}

Funding from the Canadian Institutes of Health Research, Alberta Innovates - Health Solutions (AIHS), Heart and Stroke Foundation of Canada, and the Canadian Stroke Network, supports research in the Thompson lab. RJT holds a Scholar award from AIHS and a New Investigator Award from the Heart and Stroke Foundation of Canada. NLW holds an AIHS studentship. SSS was the recipient of a Canadian Stroke Network Summer Studentship.

\section{References}

1 Zhang S, Boyd J, Delaney K, Murphy TH. Rapid reversible changes in dendritic spine structure in vivo gated by the degree of ischemia. J Neurosci 2005; 25: 5333-8.

2 Winship IR, Murphy TH. In vivo calcium imaging reveals functional rewiring of single somatosensory neurons after stroke. J Neurosci 2008; 28: 6592-606.

3 Murphy TH, Li P, Betts K, Liu R. Two-photon imaging of stroke onset in vivo reveals that NMDA-receptor independent ischemic depolarization is the major cause of rapid reversible damage to dendrites and spines. J Neurosci 2008; 28: 1756-72.

4 Fleidervish IA, Gebhardt C, Astman N, Gutnick MJ, Heinemann $U$. Enhanced spontaneous transmitter release is the earliest consequence of neocortical hypoxia that can explain the disruption of normal circuit function. J Neurosci 2001; 21: 4600-8.

5 Rossi DJ, Oshima T, Attwell D. Glutamate release in severe brain ischaemia is mainly by reversed uptake. Nature 2000; 403: 316-21.

6 Thomson AM, Walker VE, Flynn DM. Glycine enhances NMDAreceptor mediated synaptic potentials in neocortical slices. Nature 1989; 338: 422-4.

7 Johnson JW, Ascher P. Glycine potentiates the NMDA response in cultured mouse brain neurons. Nature 1987; 325: 529-31.

8 Mothet JP, Parent AT, Wolosker H, Brady RO Jr, Linden DJ, Ferris CD, et al. $D$-serine is an endogenous ligand for the glycine site of the $\mathrm{N}$-methyl-D-aspartate receptor. Proc Natl Acad Sci U S A 2000; 97 : 4926-31.

9 Kleckner NW, Dingledine R. Requirement for glycine in activation of NMDA-receptors expressed in Xenopus oocytes. Science 1988; 241 : 835-7.

10 Mayer ML, Westbrook GL, Guthrie PB. Voltage-dependent block by $\mathrm{Mg}^{2+}$ of NMDA responses in spinal cord neurones. Nature 1984; 309: 261-3.

11 Monyer H, Sprengel R, Schoepfer R, Herb A, Higuchi M, Lomeli $\mathrm{H}$, et al. Heteromeric NMDA receptors: molecular and functional distinction of subtypes. Science 1992; 256: 1217-21.

12 Laube BJ, Kuhse, Betz H. Evidence for a tetrameric structure of recombinant NMDA receptors. J Neurosci 1998; 18: 2954-61.
13 Laube B, Hirai H, Sturgess M, Betz H, Kuhse J. Molecular determinants of agonist discrimination by NMDA receptor subunits: analysis of the glutamate binding site on the NR2B subunit. Neuron 1997; 18: 493-503.

14 Kutsuwada T, Kashiwabuchi N, Mori H, Sakimura K, Kushiya E, Araki $\mathrm{K}$, et al. Molecular diversity of the NMDA receptor channel. Nature 1992; 358: 36-41.

15 Das S, Sasaki YF, Rothe T, Premkumar LS, Takasu M, Crandall JE, et al. Increased NMDA current and spine density in mice lacking the NMDA receptor subunit NR3A. Nature 1998; 393: 377-81.

16 Nakanishi N, Tu S, Shin Y, Cui J, Kurokawa T, Zhang D, et al. Neuroprotection by the NR3A subunit of the NMDA receptor. J Neurosci 2009; 29: 5260-5.

17 Sattler R, Xiong Z, Lu WY, Hafner M, MacDonald JF, Tymianski M. Specific coupling of NMDA receptor activation to nitric oxide neurotoxicity by PSD-95 protein. Science 1999; 284: 1845-8.

18 Bal-Price A, Brown GC. Inflammatory neurodegeneration mediated by nitric oxide from activated glia-inhibiting neuronal respiration, causing glutamate release and excitotoxicity. J Neurosci 2001; 21 : 6480-91.

19 Cooper CE, Giulivi C. Nitric oxide regulation of mitochondrial oxygen consumption II: Molecular mechanism and tissue physiology. Am J Physiol Cell Physiol 2007; 292: C1993-2003.

20 Lancaster JR Jr. Nitroxidative, nitrosative, and nitrative stress: kinetic predictions of reactive nitrogen species chemistry under biological conditions. Chem Res Toxicol 2006; 19: 1160-74.

21 Yamashima T. $\mathrm{Ca}^{2+}$-dependent proteases in ischemic neuronal death: a conserved 'calpain-cathepsin cascade' from nematodes to primates. Cell Calcium 2004; 36: 285-93.

22 Rasola A, Bernardi P. Mitochondrial permeability transition in $\mathrm{Ca}^{2+}$ dependent apoptosis and necrosis. Cell Calcium 2011; 50: 222-33.

23 Ikonomidou C, Turski L. Why did NMDA receptor antagonists fail clinical trials for stroke and traumatic brain injury? Lancet Neurol 2002; 1: 383-6.

24 Lee JM, Zipfel GJ, Choi DW. The changing landscape of ischaemic brain injury mechanisms. Nature 1999; 399: A7-14.

25 Liu Y, Wong TP, Aarts M, Rooyakkers A, Liu L, Lai TW, et al. NMDA receptor subunits have differential roles in mediating excitotoxic neuronal death both in vitro and in vivo. J Neurosci 2007; 27: 284657.

26 Hardingham GE, Bading $H$. Synaptic versus extrasynaptic NMDA receptor signalling: implications for neurodegenerative disorders. Nat Rev Neurosci 2010; 11: 682-96.

27 Buchan AM, Lesiuk H, Barnes KA, Li H, Huang ZG, Smith KE, et al. AMPA antagonists: do they hold more promise for clinical stroke trials than NMDA antagonists? Stroke 1993; 24: 1148-52.

28 Sheardown MJ, Nielsen EO, Hansen AJ, Jacobsen P, Honoré T. 2,3Dihydroxy-6-nitro-7-sulfamoyl-benzo(F)quinoxaline: a neuroprotectant for cerebral ischemia. Science 1990; 247: 571-4.

29 Buchan AM, Li H, Cho S, Pulsinelli WA. Blockade of the AMPA receptor prevents CA1 hippocampal injury following severe but transient forebrain ischemia in adult rats. Neurosci Lett 1991; 132: 255-8.

30 Wenthold RJ, Petralia RS, Blahos J II, Niedzielski AS. Evidence for multiple AMPA receptor complexes in hippocampal CA1/CA2 neurons. J Neurosci 1996; 16: 1982-9.

31 Jonas P, Racca C, Sakmann B, Seeburg PH, Monyer H. Differences in $\mathrm{Ca}^{2+}$ permeability of AMPA-type glutamate receptor channels in neocortical neurons caused by differential GluR-B subunit expression. Neuron 1994; 12: 1281-9.

32 Shi Y, Lu W, Milstein AD, Nicoll RA. The stoichiometry of AMPA receptors and TARPs varies by neuronal cell type. Neuron 2009; 62: 
633-40.

33 Burnashev N, Monyer H, Seeburg PH, Sakmann B. Divalent ion permeability of AMPA receptor channels is dominated by the edited form of a single subunit. Neuron 1992; 8: 189-98.

34 Liu S, Lau L, Wei J, Zhu D, Zou S, Sun HS, et al. Expression of $\mathrm{Ca}^{2+}$ permeable AMPA receptor channels primes cell death in transient forebrain ischemia. Neuron 2004; 43: 43-55.

35 Hollmann M, Hartley M, Heinemann S. $\mathrm{Ca}^{2+}$ permeability of KAAMPA - gated glutamate receptor channels depends on subunit composition. Science 1991; 252: 851-3.

36 Verdoorn TA, Burnashev N, Monyer H, Seeburg PH, Sakmann B. Structural determinants of ion flow through recombinant glutamate receptor channels. Science 1991; 252: 1715-8.

37 Noh KM, Yokota H, Mashiko T, Castillo PE, Zukin RS, Bennett MV. Blockade of calcium-permeable AMPA receptors protects hippocampal neurons against global ischemia-induced death. Proc Natl Acad Sci U S A 2005; 102: 12230-5.

38 Tanaka H, Grooms SY, Bennett MV, Zukin RS. The AMPAR subunit GluR2: still front and center-stage. Brain Res 2000; 886: 190-207.

39 Gorter JA, Petrozzino JJ, Aronica EM, Rosenbaum DM, Opitz T, Bennett MV, et al. Global ischemia induces downregulation of Glur2 mRNA and increases AMPA receptor-mediated $\mathrm{Ca}^{2+}$ influx in hippocampal CA1 neurons of gerbil. J Neurosci 1997; 17: 6179-88.

40 Pellegrini-Giampietro DE, Zukin RS, Bennett MV, Cho S, Pulsinelli WA. Switch in glutamate receptor subunit gene expression in CA1 subfield of hippocampus following global ischemia in rats. Proc Natl Acad Sci U S A 1992; 89: 10499-503.

41 Zhou Y, Zhou L, Chen H, Koliatsos VE. An AMPA glutamatergic receptor activation - nitric oxide synthesis step signals transsynaptic apoptosis in limbic cortex. Neuropharmacology 2006; 51: 67-76.

42 Araujo IM, Verdasca MJ, Leal EC, Bahr BA, Ambrósio AF, Carvalho AP, et al. Early calpain-mediated proteolysis following AMPA receptor activation compromises neuronal survival in cultured hippocampal neurons. J Neurochem 2004; 91: 1322-31.

43 Zhang QG, Han D, Hu SQ, Li C, Yu CZ, Wang R, et al. Positive modulation of AMPA receptors prevents downregulation of GluR2 expression and activates the Lyn-ERK1/2-CREB signaling in rat brain ischemia. Hippocampus 2010; 20: 65-77.

44 Burnstock G. Physiology and pathophysiology of purinergic neurotransmission. Physiol Rev 2007; 87: 659-797.

45 Matute C, Cavaliere F. Neuroglial interactions mediated by purinergic signalling in the pathophysiology of CNS disorders. Semin Cell Dev Biol 2011; 22: 252-9.

46 Bolas NM, Rajagopalan B, Mitsumori F, Radda GK. Metabolic changes during experimental cerebral ischemia in hyperglycemic rats, observed by ${ }^{31} \mathrm{P}$ and ${ }^{1} \mathrm{H}$ magnetic resonance spectroscopy. Stroke 1988; 19: 608-14.

47 Whittingham TS, Lust WD, Passonneau JV. An in vitro model of ischemia: metabolic and electrical alterations in the hippocampal slice. J Neurosci 1984; 4: 793-802.

48 Katsura K, Rodriguez de Turco EB, Folbergrová J, Bazan NG, Siesjö BK. Coupling among energy failure, loss of ion homeostasis, and phospholipase A2 and C activation during ischemia. J Neurochem 1993; 61: 1677-84.

49 Frenguelli BG, Wigmore G, Llaudet E, Dale N. Temporal and mechanistic dissociation of ATP and adenosine release during ischaemia in the mammalian hippocampus. J Neurochem 2007; 101: 1400-13.

50 Surprenant A, Rassendren F, Kawashima E, North RA, Buell G. The cytolytic P2Z receptor for extracellular ATP identified as a P2X receptor (P2X7). Science 1996; 272: 735-8.

51 Le Feuvre RA, Brough D, Touzani O, Rothwell NJ. Role of P2X7 receptors in ischemic and excitotoxic brain injury in vivo. J Cereb Blood Flow Metab 2003; 23: 381-4.

52 Skaper SD, Debetto P, Giusti P. The P2X7 purinergic receptor: from physiology to neurological disorders. FASEB J 2010; 24: 337-45.

53 Pelegrin P, Surprenant A. Pannexin-1 mediates large pore formation and interleukin-1beta release by the ATP-gated P2X7 receptor. EMBO J 2006; 25: 5071-82.

54 Locovei SJ, Wang J, Dahl G. Activation of pannexin 1 channels by ATP through P2Y receptors and by cytoplasmic calcium. FEBS Lett 2006; 580: 239-44.

55 MacVicar BA, Thompson RJ. Non-junction functions of pannexin-1 channels. Trends Neurosci 2010; 33: 93-102.

56 Juranyi ZB, Sperlagh B, Vizi ES. Involvement of P2 purinoceptors and the nitric oxide pathway in $\left.{ }^{3} \mathrm{H}\right]$ purine outflow evoked by short-term hypoxia and hypoglycemia in rat hippocampal slices. Brain Res 1999; 823: 183-90.

57 Melani A, Turchi D, Vannucchi MG, Cipriani S, Gianfriddo M, Pedata F. ATP extracellular concentrations are increased in the rat striatum during in vivo ischemia. Neurochem Int 2005; 47: 442-8.

58 Zhang Z, Chen G, Zhou W, Song A, Xu T, Luo Q, et al. Regulated ATP release from astrocytes through lysosome exocytosis. Nat Cell Biol 2007; 9: 945-53.

59 Iglesias R, Dahl G, Qiu F, Spray DC, Scemes E. Pannexin 1: the molecular substrate of astrocyte "hemichannels". J Neurosci 2009; 29: 7092-7.

60 Schock SC, Leblanc D, Hakim AM, Thompson CS. ATP release by way of connexin 36 hemichannels mediates ischemic tolerance in vitro. Biochem Biophys Res Commun 2008; 368: 138-44.

61 Huckstepp RT, id Bihi R, Eason R, Spyer KM, Dicke N, Willecke K, et al. Connexin hemichannel-mediated $\mathrm{CO}_{2}$-dependent release of ATP in the medulla oblongata contributes to central respiratory chemosensitivity. J Physiol 2010; 588: 3901-20.

62 Ballerini P, Di lorio P, Ciccarelli R, Nargi E, D'Alimonte I, Traversa U, et al. Glial cells express multiple ATP binding cassette proteins which are involved in ATP release. Neuroreport 2002; 13: 1789-92.

63 Darby M, Kuzmiski JB, Panenka W, Feighan D, MacVicar BA. ATP released from astrocytes during swelling activates chloride channels. J Neurophysiol 2003; 89: 1870-7.

64 Chekeni FB, Elliott MR, Sandilos JK, Walk SF, Kinchen JM, Lazarowski $\mathrm{ER}$, et al. Pannexin 1 channels mediate 'find-me' signal release and membrane permeability during apoptosis. Nature 2010; 467: 863-7.

65 Locovei S, Scemes E, Qiu F, Spray DC, Dahl G. Pannexin1 is part of the pore forming unit of the P2X(7) receptor death complex. FEBS Lett 2007; 581: 483-8.

66 Burnstock G, Krügel U, Abbracchio MP, Illes P. Purinergic signalling: from normal behaviour to pathological brain function. Prog Neurobiol 2011; 95: 229-74.

67 Cavaliere F, Amadio S, Dinkel K, Reymann KG, Volonté C. P2 receptor antagonist trinitrophenyl - adenosine-triphosphate protects hippocampus from oxygen and glucose deprivation cell death. J Pharmacol Exp Ther 2007; 323: 70-7.

68 Cavaliere F, Florenzano F, Amadio S, Fusco FR, Viscomi MT, D'Ambrosi $\mathrm{N}$, et al. Up-regulation of $\mathrm{P} 2 \mathrm{X} 2, \mathrm{P} 2 \mathrm{X} 4$ receptor and ischemic cell death: prevention by P2 antagonists. Neuroscience 2003; 120 : 85-98.

69 Cavaliere F, Sancesario G, Bernardi G, Volonté C. Extracellular ATP and nerve growth factor intensify hypoglycemia-induced cell death in primary neurons: role of P2 and NGFRp75 receptors. J Neurochem 2002; 83: 1129-38.

70 Arbeloa J, Pérez-Samartín A, Gottlieb M, Matute C. P2X7 receptor blockade prevents ATP excitotoxicity in neurons and reduces brain 
damage after ischemia. Neurobiol Dis 2012; 45: 954-61.

71 Domercq M, Perez-Samartin A, Aparicio D, Alberdi E, Pampliega O, Matute C. P2X7 receptors mediate ischemic damage to oligodendrocytes. Glia 2010; 58: 730-40.

72 Lammer A, Günther A, Beck A, Krügel U, Kittner H, Schneider D, et al. Neuroprotective effects of the P2 receptor antagonist PPADS on focal cerebral ischaemia-induced injury in rats. Eur J Neurosci 2006; 23: 2824-8.

73 Lammer AB, Beck A, Grummich B, Förschler A, Krügel T, Kahn T, et al. The P2 receptor antagonist PPADS supports recovery from experimental stroke in vivo. PLoS One 2011; 6: e19983.

74 Domercq M, Perez-Samartin A, Aparicio D, Alberdi E, Pampliega O, Matute C. P2X7 receptors mediate ischemic damage to oligodendrocytes. Glia 2010; 58: 730-40.

75 Traini C, Pedata F, Cipriani S, Mello T, Galli A, Giovannini MG, et al. P2 receptor antagonists prevent synaptic failure and extracellular signal-regulated kinase $1 / 2$ activation induced by oxygen and glucose deprivation in rat CA1 hippocampus in vitro. Eur J Neurosci 2011; 33: 2203-15.

76 Dunwiddie TV. Endogenously released adenosine regulates excitability in the in vitro hippocampus. Epilepsia 1980; 21: 541-8.

77 Masino SA, Diao L, Illes P, Zahniser NR, Larson GA, Johansson B, et al. Modulation of hippocampal glutamatergic transmission by ATP is dependent on adenosine a(1) receptors. J Pharmacol Exp Ther 2002; 303: 356-63.

78 Malva JO, Silva AP, Cunha RA. Presynaptic modulation controlling neuronal excitability and epileptogenesis: role of kainate, adenosine and neuropeptide $Y$ receptors. Neurochem Res 2003; 28: 1501-15.

79 Melani A, Cipriani S, Vannucchi MG, Nosi D, Donati C, Bruni P, et al. Selective adenosine A2a receptor antagonism reduces JNK activation in oligodendrocytes after cerebral ischaemia. Brain 2009; 132: 1480-95.

80 Chen GJ, Harvey BK, Shen H, Chou J, Victor A, Wang Y. Activation of adenosine $A 3$ receptors reduces ischemic brain injury in rodents. J Neurosci Res 2006; 84: 1848-55.

81 Braun N, Zhu Y, Krieglstein J, Culmsee C, Zimmermann H. Upregulation of the enzyme chain hydrolyzing extracellular ATP after transient forebrain ischemia in the rat. J Neurosci 1998; 18: 4891-900.

82 Zimmermann H. Ectonucleotidases in the nervous system. Novartis Found Symp 2006; 276: 113-28; discussion 128-30, 233-7, 27581.

83 Pedata F, Melani A, Pugliese AM, Coppi E, Cipriani S, Traini C. The role of ATP and adenosine in the brain under normoxic and ischemic conditions. Purinergic Signal 2007; 3: 299-310.

84 Pugliese AM, Traini C, Cipriani S, Gianfriddo M, Mello T, Giovannini MG, et al. The adenosine A2A receptor antagonist ZM241385 enhances neuronal survival after oxygen-glucose deprivation in rat CA1 hippocampal slices. Br J Pharmacol 2009; 157: 818-30.

85 Daval JL, Von Lubitz DK, Deckert J, Redmond DJ, Marangos PJ. Protective effect of cyclohexyladenosine on adenosine A1-receptors, guanine nucleotide and forskolin binding sites following transient brain ischemia: a quantitative autoradiographic study. Brain Res 1989; 491: 212-26.

86 Von Lubitz DK, Lin RC, Melman N, Ji XD, Carter MF, Jacobson KA. Chronic administration of selective adenosine $\mathrm{A} 1$ receptor agonist or antagonist in cerebral ischemia. Eur J Pharmacol 1994; 256: 161-7.

87 Von Lubitz DK, Lin RC, Popik P, Carter MF, Jacobson KA. Adenosine A3 receptor stimulation and cerebral ischemia. Eur J Pharmacol 1994; 263: 59-67.

88 Von Lubitz DK, Lin RC, Melman N, Ji XD, Carter MF, Jacobson KA. Chronic NMDA receptor stimulation: therapeutic implications of its effect on adenosine A1 receptors. Eur J Pharmacol 1995; 283:
185-92.

89 Von Lubitz DK, Lin RC, Jacobson KA. Cerebral ischemia in gerbils: effects of acute and chronic treatment with adenosine A2A receptor agonist and antagonist. Eur J Pharmacol 1995; 287: 295-302.

90 Von Lubitz DK, Lin RC, Paul IA, Beenhakker M, Boyd M, Bischofberger $\mathrm{N}$, et al. Postischemic administration of adenosine amine congener (ADAC): analysis of recovery in gerbils. Eur J Pharmacol 1996; 316: 171-9.

91 Monopoli A, Lozza G, Forlani A, Mattavelli A, Ongini E. Blockade of adenosine A2A receptors by $\mathrm{SCH} 58261$ results in neuroprotective effects in cerebral ischaemia in rats. Neuroreport 1998; 9: 3955-9.

92 Cassada DC, Tribble CG, Laubach VE, Nguyen BN, Rieger JM, Linden $\mathrm{J}$, et al. An adenosine A2A agonist, ATL-146e, reduces paralysis and apoptosis during rabbit spinal cord reperfusion. J Vasc Surg 2001; 34: 482-8.

93 Latini S, Bordoni F, Corradetti R, Pepeu G, Pedata F. Effect of A2A adenosine receptor stimulation and antagonism on synaptic depression induced by in vitro ischaemia in rat hippocampal slices. $\mathrm{Br} \mathrm{J}$ Pharmacol 1999; 128: 1035-44.

94 Pugliese AM, Coppi E, Spalluto G, Corradetti R, Pedata F. A3 adenosine receptor antagonists delay irreversible synaptic failure caused by oxygen and glucose deprivation in the rat CA1 hippocampus in vitro. Br J Pharmacol 2006; 147: 524-32.

95 Pugliese AM, Coppi E, Volpini R, Cristalli G, Corradetti R, Jeong LS, et al. Role of adenosine A3 receptors on CA1 hippocampal neurotransmission during oxygen-glucose deprivation episodes of different duration. Biochem Pharmacol 2007; 74: 768-79.

96 Chen JF, Huang Z, Ma J, Zhu J, Moratalla R, Standaert D, et al. A(2A) adenosine receptor deficiency attenuates brain injury induced by transient focal ischemia in mice. J Neurosci 1999; 19: 9192-200.

97 Panchin Y, Kelmanson I, Matz M, Lukyanov K, Usman N, Lukyanov S. A ubiquitous family of putative gap junction molecules. Curr Biol 2000; 10: R473-4.

98 Baranova A, Ivanov D, Petrash N, Pestova A, Skoblov M, Kelmanson I, et al. The mammalian pannexin family is homologous to the invertebrate innexin gap junction proteins. Genomics 2004; 83: 706-16.

99 Swayne LA, Sorbara CD, Bennett SA. Pannexin 2 is expressed by postnatal hippocampal neural progenitors and modulates neuronal commitment. J Biol Chem 2010; 285: 24977-86.

100 Thompson RJ, Zhou N, MacVicar BA. Ischemia opens neuronal gap junction hemichannels. Science 2006; 312: 924-7.

101 Zhang L, Deng T, Sun Y, Liu K, Yang Y, Zheng X. Role for nitric oxide in permeability of hippocampal neuronal hemichannels during oxygen glucose deprivation. J Neurosci Res 2008; 86: 2281-91.

102 Bunse S, Schmidt M, Prochnow N, Zoidl G, Dermietzel R. Intracellular cysteine 346 is essentially involved in regulating Panx1 channel activity. J Biol Chem 2010; 285: 38444-52.

103 Bargiotas P, Krenz A, Hormuzdi SG, Ridder DA, Herb A, Barakat W, et al. Pannexins in ischemia-induced neurodegeneration. Proc Natl Acad Sci U S A 2011; 108: 20772-7.

104 Locovei S, Bao L, Dahl G. Pannexin 1 in erythrocytes: function without a gap. Proc Natl Acad Sci U S A 2006; 103: 7655-9.

105 Chekeni FB, Elliott MR, Sandilos JK, Walk SF, Kinchen JM, Lazarowski $\mathrm{ER}$, et al. Pannexin 1 channels mediate 'find-me' signal release and membrane permeability during apoptosis. Nature 2010; 467: 863-7.

106 Wicki-Stordeur LE, Dzugalo AD, Swansburg RM, Suits JM. Pannexin 1 regulates postnatal neural stem and progenitor cell proliferation. Neural Dev 2012; 7: 11.

107 Thompson RJ, Jackson MF, Olah ME, Rungta RL, Hines DJ, Beazely MA, et al. Activation of pannexin-1 hemichannels augments aberrant bursting in the hippocampus. Science 2008; 322: 1555-9. 
108 Vessey DA, Li L, Kelley M. Ischemic preconditioning requires opening of pannexin-1/P2X(7) channels not only during preconditioning but again after index ischemia at full reperfusion. Mol Cell Biochem 2011; 351: 77-84.

109 Gulbransen BD, Bashashati M, Hirota SA, Gui X, Roberts JA, MacDonald JA, et al. Activation of neuronal P2X7 receptor-pannexin-1 mediates death of enteric neurons during colitis. Nat Med 2012 Mar 18. doi: 10.1038/nm.2679.

110 Iglesias R, Locovei S, Roque A, Alberto AP, Dahl G, Spray DC, et al. P2X7 receptor-Pannexin1 complex: pharmacology and signaling. Am J Physiol Cell Physiol 2008; 295: C752-60.

111 Qiu F, Dahl G. A permeant regulating its permeation pore: inhibition of pannexin 1 channels by ATP. Am J Physiol Cell Physiol 2009; 296: C250-5.

112 Pelegrin P, Barroso-Gutierrez C, Surprenant A. P2X7 receptor differentially couples to distinct release pathways for IL-1beta in mouse macrophage. J Immunol 2008; 180: 7147-57.

113 Lennmyr F, Ericsson A, Gerwins P, Akterin S, Ahlström H, Terént A. Src family kinase-inhibitor PP2 reduces focal ischemic brain injury. Acta Neurol Scand 2004; 110: 175-9.

114 Liang S, Pong K, Gonzales C, Chen Y, Ling HP, Mark RJ, et al. Neuroprotective profile of novel SRC kinase inhibitors in rodent models of cerebral ischemia. J Pharmacol Exp Ther 2009; 331: 827-35.

115 Tian HP, Huang BS, Zhao J, Hu XH, Guo J, Li LX. Non-receptor tyrosine kinase $\mathrm{Src}$ is required for ischemia-stimulated neuronal cell proliferation via Raf/ERK/CREB activation in the dentate gyrus. BMC Neurosci 2009; 10: 139.

116 Guo J, Adato R. Extended long range plasmon waves in finite thickness metal film and layered dielectric materials. Opt Express 2006; 14: 12409-18.

117 Kawamura M Jr, Ruskin DN, Masino SA. Metabolic autocrine regulation of neurons involves cooperation among pannexin hemichannels, adenosine receptors, and $\mathrm{K}_{\text {ATP }}$ channels. J Neurosci 2010; 30: 3886-95.

118 Sandilos JK, Chiu YH, Chekeni FB, Armstrong AJ, Walk SF, Ravichandran KS, et al. Pannexin 1, an ATP release channel, is activated by caspase cleavage of its pore-associated $\mathrm{C}$ terminal autoinhibitory region. J Biol Chem 2012; 287: 11303-11.

119 Santiago MF, Veliskova J, Patel NK, Lutz SE, Caille D, Charollais A, et al. Targeting pannexin1 improves seizure outcome. PLoS One 2011; 6: e25178.

120 Clapham DE, Runnels LW, Strubing C. The TRP ion channel family. Nature reviews. Neuroscience 2001; 2: 387-96.

$121 \mathrm{Wu}$ LJ, Sweet TB, Clapham DE. International Union of Basic and Clinical Pharmacology. LXXVI. Current progress in the mammalian TRP ion channel family. Pharmacol Rev 2010; 62: 381-404.

122 Aarts M, lihara K, Wei WL, Xiong ZG, Arundine M, Cerwinski W, et al. A key role for TRPM7 channels in anoxic neuronal death. Cell 2003; 115: 863-77.

123 Miller BA. Inhibition of TRPM2 function by PARP inhibitors protects cells from oxidative stress-induced death. Br J Pharmacol 2004; 143: 515-6.

124 MacDonald JF, Xiong ZG, Jackson MF. Paradox of $\mathrm{Ca}^{2+}$ signaling, cell death and stroke. Trends Neurosci 2006; 29: 75-81.

125 Aarts MM, Tymianski M. TRPMs and neuronal cell death. Pflugers Arch 2005; 451: 243-9.

126 Perraud AL, Fleig A, Dunn CA, Bagley LA, Launay P, Schmitz C, et al. ADP-ribose gating of the calcium-permeable LTRPC2 channel revealed by Nudix motif homology. Nature 2001; 411: 595-9.

127 Harteneck C. Function and pharmacology of TRPM cation channels. Naunyn Schmiedebergs Arch Pharmacol 2005; 371: 307-14.

128 Simard JM, Tarasov KV, Gerzanich V. Non-selective cation channels, transient receptor potential channels and ischemic stroke. Biochim Biophys Acta 2007; 1772: 947-57.

129 Cook DJ, Teves L, Tymianski M. Treatment of stroke with a PSD95 inhibitor in the gyrencephalic primate brain. Nature 2012; 483: 213-7.

130 Sun HS, Jackson MF, Martin L, Jansen K, Teves L, Cui H, et al. Suppression of hippocampal TRPM7 protein prevents delayed neuronal death in brain ischemia. Nat Neurosci 2009; 12: 1300-7.

131 Montell C, Birnbaumer L, Flockerzi V. The TRP channels, a remarkably functional family. Cell 2002; 108: 595-8.

132 Zhang W, Chu X, Tong Q, Cheung JY, Conrad K, Masker K, et al. A novel TRPM2 isoform inhibits calcium influx and susceptibility to cell death. J Biol Chem 2003; 278: 16222-9.

133 Fonfria E, Mattei C, Hill K, Brown JT, Randall A, Benham CD, et al. TRPM2 is elevated in the TMCAO stroke model, transcriptionally regulated, and functionally expressed in C13 microglia. J Recept Signal Transduct Res 2006; 26: 179-98.

134 Xiong ZG, Chu XP, Simon RP. $\mathrm{Ca}^{2+}$-permeable acid-sensing ion channels and ischemic brain injury. J Membr Biol 2006; 209: 5968.

135 Isaev NK, Stelmashook EV, Plotnikov EY, Khryapenkova TG, Lozier ER, Doludin YV, et al. Role of acidosis, NMDA receptors, and acidsensitive ion channel 1a (ASIC1a) in neuronal death induced by ischemia. Biochemistry (Mosc) 2008; 73: 1171-5.

136 Xiong ZG, Zhu XM, Chu XP, Minami M, Hey J, Wei WL, et al. Neuroprotection in ischemia: blocking calcium-permeable acid-sensing ion channels. Cell 2004; 118: 687-98.

137 Yermolaieva O, Leonard AS, Schnizler MK, Abboud FM, Welsh MJ. Extracellular acidosis increases neuronal cell calcium by activating acid-sensing ion channel 1a. Proc Natl Acad Sci U S A 2004; 101: 6752-7.

138 Krishtal O. The ASICs: signaling molecules? Modulators? Trends Neurosci 2003; 26: 477-83.

139 Waldmann R, Champigny G, Bassilana F, Heurteaux C, Lazdunski M. A proton-gated cation channel involved in acid-sensing. Nature 1997; 386: 173-7.

140 Gonzales EB, Kawate T, Gouaux E. Pore architecture and ion sites in acid-sensing ion channels and P2X receptors. Nature 2009; 460: 599-604.

141 Jasti J, Furukawa H, Gonzales EB, Gouaux E. Structure of acidsensing ion channel 1 at 1.9 A resolution and low pH. Nature 2007; 449: 316-23.

142 Paukert M, Chen X, Polleichtner G, Schindelin H, Gründer S. Candidate amino acids involved in $\mathrm{H}^{+}$gating of acid-sensing ion channel 1a. J Biol Chem 2008; 283: 572-81.

143 Grunder S, Chen X. Structure, function, and pharmacology of acid-sensing ion channels (ASICs): focus on ASIC1a. Int J Physiol Pathophysiol Pharmacol 2010; 2: 73-94.

144 Pignataro G, Simon RP, Xiong ZG. Prolonged activation of ASIC1a and the time window for neuroprotection in cerebral ischaemia. Brain 2007; 130: 151-8.

145 Gao J, Duan B, Wang DG, Deng XH, Zhang GY, Xu L, et al. Coupling between NMDA receptor and acid-sensing ion channel contributes to ischemic neuronal death. Neuron 2005; 48: 635-46.

146 Duan B, Wang YZ, Yang T, Chu XP, Yu Y, Huang Y, et al. Extracellular spermine exacerbates ischemic neuronal injury through sensitization of ASIC1a channels to extracellular acidosis. J Neurosci 2011; 31: 2101-12.

147 Sherwood TW, Askwith CC. Dynorphin opioid peptides enhance acidsensing ion channel 1 a activity and acidosis-induced neuronal death. J Neurosci 2009; 29: 14371-80. 